\title{
O LEITOR QUE ME TORNEI: EXPERIÊNCIAS E CONCEPÇÕES DE FUTUROS PROFESSORES DE INGLÊS SOBRE A LEITURA
}

\begin{abstract}
The reader I came to be: experiences and views of future English teachers about reading
\end{abstract}

Simone REIS, UEL ${ }^{1}$

Rafael Leonardo da SILVA ${ }^{2}$

RESUMO: Este artigo analisa dados do projeto de pesquisa Pensamento Crítico para Ação Transformadora, que visa contribuir para o desenvolvimento da área de pesquisa de Letramento Crítico em língua estrangeira no Brasil. Adotamos visão construcionista social do conhecimento (SCHWANDT, 2006). Tal visão é subjetiva, e considera a linguagem um instrumento de poder construído socialmente. No presente artigo, narrativas de futuros professores são analisadas a respeito de suas experiências de leitura desde a infância até sua entrada no curso de graduação de Letras - Inglês e Respectivas Literaturas da Universidade Estadual de Londrina. Tais narrativas foram uma tarefa escrita da disciplina intitulada Leitura em Língua Inglesa no ano de 2012. Procuramos identificar (1) a relação destes alunos com a leitura, (2) os gêneros que eles leem, bem como (3) experiências que eles têm em comum. Nossa interpretação aponta para influências externas aos leitores em seu desenvolvimento e sua visão positiva sobre a leitura na infância como fator determinante para o desenvolvimento deste hábito. Mostra, também, que enquanto os alunos exercem agência através de suas escolhas de leitura na adolescência, é nesta fase e na vida adulta, neste caso, na universidade, que as leituras obrigatórias parecem não ser tão apreciadas. Enquanto a leitura recreativa na vida adulta se torna quase inexistente nas narrativas analisadas, a leitura de textos acadêmicos é considerada importante e/ou necessária para o desenvolvimento profissional.

PALAVRAS-CHAVE: Educação de professores de inglês; educação de leitores; narrativa.

ABSTRACT: This article analyses data from the research project "Pensamento Crítico para Ação Transformadora" (Critical Thinking for Transformative Action), which aims at contributing to the development of the research area of Critical Literacy in foreign language in Brazil. We adopt a social constructionist view of knowledge (SCHWANDT, 2006). This view is subjective, and assumes language to be a socially constructed power instrument. In this paper, narratives of prospective teachers are analyzed in regard with their reading experiences since childhood until their entrance in the undergraduate course of English Language and Literature from the State University of Londrina, Brazil.. Such narratives were a writing assignment of the course subject entitled, Leitura em Língua Inglesa (Reading in English language) in the year of 2012. We aim at identifying (1) the relationships of the students with reading, (2) the genres which they read, as well as (3) experiences which they have in common. Our interpretation points to external influences to the readers in their development and their

\footnotetext{
${ }^{1}$ Professora Adjunta no Departamento de Letras Estrangeiras Modernas na Universidade Estadual de Londrina (UEL). Doutora em Ciências Sociais pela Radboud Universiteit Nijmegen (Holanda, 2005). Docente do Programa de Pós-Graduação em Estudos da Linguagem da UEL desde 2006.

${ }^{2}$ Mestrando em Estudos da Linguagem pela UEL.
} 
positive view about reading in childhood as a determining factor for the development of such habit. It also shows that while students exert agency by means of their choices of reading in adolescence, it is in this phase and in adulthood, namely at university, that compulsory reading seems to be not that much appreciated. While leisure reading in adulthood becomes almost non-existent in the narratives analyzed, reading of academic texts is accounted for as important and or necessary for professional development.

KEYWORDS: English language teacher education; reading education; narrative.

\section{INTRODUÇÃO}

Este trabalho examina dados do projeto de pesquisa "Pensamento Crítico para Ação Transformadora" (PPCAT). Neste projeto, buscamos contribuir para o desenvolvimento da pesquisa em Letramento Crítico em língua estrangeira no Brasil, uma vez que documentos como as Orientações Curriculares para o Ensino Médio (OCEM) e os Parâmetros Curriculares Nacionais (PCN) consideram, em todas as disciplinas escolares, a qualidade crítica como essencial para o professor e o material por ele utilizado e/ou preparado. Tal qualidade é entendida nestes documentos como necessária ao desenvolvimento tanto da responsabilidade social do indivíduo como de sua autonomia. Nesse contexto, o estudo da educação de leitores, objeto do presente relato, se faz importante.

Adotamos, neste artigo, a visão de língua como fenômeno social, e, portanto, influenciada pelo poder, que é distribuído desigualmente (FAIRCLOUGH, 1989). Nosso posicionamento epistemológico é construcionista social (SCHWANDT, 2006), considerando que o indivíduo transforma o conhecimento e é por ele transformado. Essa epistemologia converge com a visão discursiva de linguagem-instrumento de poder, por ser perspectiva com a qual interpretamos o mundo e as relações sociais. Desse modo, o conhecimento não possui significado estável; ele é necessariamente inacabado, contextual, provisório, como são as construções sociais.

Aqui, analisamos narrativas de experiência de leitura de alunos do segundo ano do curso de Letras Estrangeiras Modernas da Universidade Estadual de Londrina (UEL). Nossas análises das narrativas permitem aos alunos conhecerem que suas experiências não são isoladas (BENJAMIN, 1999), assim como nos possibilitam compreender concepções e visões sobre leitura de alunos, bem como seu posicionamento atual e projeções futuras na posição de professores de língua 
estrangeira. Possibilita-lhes, também, tomar consciência dos processos formativos de leitura, assim como identificar-se com aspectos das narrativas analisadas.

\section{FUNDAMENTAÇÃO TEÓRICA}

\subsection{Construcionismo Social}

A concepção construcionista social postula que o conhecimento é adquirido pelas experiências de cada indivíduo, que interpretará suas vivências de acordo com o seu conhecimento prévio e as assimilará por meio de negociação de interpretações (SCHWANDT, 2006). Assim, o construcionismo social rejeita a ideia de que há uma realidade concreta, defendendo o pressuposto de que o ser humano desenvolve sua própria realidade dependente dos contextos em que vive (HALLING \& LAWRENCE, 1999).

É importante mencionar que a interação entre indivíduos nem sempre é simétrica; a ela subjazem relações de poder, que interditam os discursos (FOUCAULT, 2001; 1970). Por isso, até mesmo situações banais, como uma simples conversa com uma pessoa mais experiente ou uma consulta médica apresentam um interlocutor que está em uma posição mais favorável e outro em posição inferior. As relações de poder, neste artigo, permeiam o discurso dos alunos em suas descrições sobre seus mentores e instituições por eles frequentadas.

Essas relações de poder são criadas por meio da linguagem, que é permeada de intenções e ideologias de um indivíduo (SCHWANDT, 2006). A importância da linguagem nas interações também é enfatizada por Fairclough (1989), que acrescenta que diferentes meios sociais podem modificar o discurso. Por exemplo, a maneira pela qual uma pessoa se dirige a seus pais não é a mesma utilizada para interagir com colegas de trabalho. Desse modo, o discurso é modificado e, por consequência, também as relações de poder.

Esta concepção construcionista social nos ajuda a compreender como se dá o desenvolvimento da leitura de alunos, por meio de análise de seu papel de agentes externos e sua importância na evolução destes indivíduos. 


\subsection{Narrativa de experiência}

Narrativa é uma sequência de eventos que ocorrem a um ser ou um grupo de seres, sejam humanos, animais ou outros. Esta sequência de eventos é, na maioria das vezes, apresentada em ordem cronológica, e pode cobrir um curto ou um longo período de tempo, bem como uma curta (no caso de contos) ou longa (no caso de romances) narração (BERGER, 1997 apud OZYLDIRIM, 2009). A narrativa é um tipo textual que pode ser encontrado em grande variedade de gêneros textuais ${ }^{3}$, como a fábula, a crônica, a narrativa de experiência pessoal, entre outros (MARCUSCHI, 2002).

A narrativa de experiência pessoal é, para Labov (1997), enquanto gênero, uma sequência de eventos que compõem a biografia de um indivíduo. Assim, o indivíduo é parte integrante dos acontecimentos que são narrados, o que possibilita com que este avalie de maneira social e emocional à sua experiência, diferenciando a narrativa de experiência pessoal de uma simples recordação de eventos.

Na narrativa pessoal, utiliza-se a primeira pessoa do singular, quando se trata das experiências do próprio narrador, que discorre sobre os acontecimentos relatados sob o seu ponto de vista. É recorrente, também, o uso da terceira pessoa do singular e do plural. Tal uso geralmente permite encaminhar descrições, análises e também críticas sobre o que é narrado. As narrativas também admitem que se narre sobre terceiro(s), sendo que o narrador pode assumir posições oniciente e onipresente em relação ao narrado.

Benjamin (1999), por sua vez, apresenta uma visão da experiência como algo não pertencente apenas ao indivíduo, mas também a diferentes pessoas que podem compartilhar dessas experiências em outros contextos. Além disso, ele considera as narrativas de experiências como capazes de resistir ao tempo e serem reinterpretadas. $\mathrm{O}$

\footnotetext{
${ }^{3}$ Gêneros textuais, neste artigo, são “formas relativamente estáveis” de textos (BAKHTIN, 1992, p. 297), passíveis de modificação, conforme o meio social e a necessidade comunicativa das situações em que são utilizados, daí sua relativa estabilidade (BRONCKART, 1999). Gênero textual distingue-se de tipo textual. O primeiro não tem um conjunto restrito de regras próprias. Há também um número incontável de gêneros, pois estes são criados dependendo da necessidade do contexto. Já a tipologia textual, para Marcuschi (2002), se apresenta em apenas cinco formas, a saber: a narração, descrição, dissertação, informação e injunção. Os gêneros textuais podem apresentar mais de um tipo textual em sua composição. Apesar de sua característica "relativamente estável", alguns gêneros possuem características específicas e são restritos a determinados meios sociais. O culto e a oração, por exemplo, são gêneros textuais encontrados em contextos religiosos. Diferentemente destes gêneros, a narrativa de experiência, utilizada pelos sujeitos de trabalho para relatar suas vivências em relação à leitura, tem sua organização dependente do conteúdo que está sendo narrado.
} 
autor diferencia "experiência" de "informação", sendo a função desta última cumprida assim que é transmitida, e não é mais reproduzida, não resistindo ao tempo.

No âmbito das narrativas aqui analisadas, sua escrita possibilitou aos alunos relatarem suas vivências relacionadas às práticas de leitura não apenas como fatos desprovidos de significado. Em nossa análise, apontaremos vestígios de autocrítica dos alunos em relação a determinados aspectos de sua biografia de leitores.

\section{METODOLOGIA}

Participaram da pesquisa 16 alunos do segundo ano do curso de Letras - Inglês e Respectivas Literaturas da UEL. Eles produziram os textos, aqui analisados, para a disciplina intitulada Leitura em Língua Inglesa: aspectos teóricos, ministrada pela segunda autora deste artigo, em Março de 2012.

A disciplina objetiva conscientizar os alunos sobre diferentes concepções de leitura e lhes oportunizar diferentes práticas de leitura, para que estes ampliem suas visões de leitura. Dessa maneira, podem ser formados leitores mais autônomos e críticos. As leituras feitas durante esta disciplina variam de textos teóricos a exemplos que são analisados com base nas teorias cotejadas.

A escrita das narrativas pessoais de experiência foi feita extraclasse, de modo que os alunos dispusessem de tempo para refletirem sobre suas vivências e organizá-las em suas produções. Cada aluno enviou seu texto por e-mail à professora da disciplina, que posteriormente solicitou sua autorização para utilização como dados desta pesquisa, para a qual não houve qualquer objeção.

Para melhor organizar narrativas escritas, procedemos à sua codificação individual alfanumérica $(\mathrm{N}=$ noturno; $\mathrm{V}$ = vespertino; e numeração crescente, a partir de 1, de cada turno). Exemplo: N1 e N2 correspondem a alunos do período noturno, enquanto V1 e V2, a do período vespertino. Os dados foram analisados qualitativamente, tendo como finalidade responder estas perguntas de pesquisa:

1) Que os gêneros de leitura compõem a vida de alunos desde sua infância à vida adulta?

2) Que relações os alunos estabeleceram com a leitura em cada fase?

3) Que experiências (sociais e acadêmicas) são recorrentes nas narrativas dos alunos? 


\subsection{Método de análise}

Conduzimos uma análise indutiva e dedutiva, realizando o levantamento de temas mais comuns nas produções dos alunos, procurando responder às questões norteadoras desta pesquisa.

Primeiramente, analisamos as narrativas dos alunos indutivamente, procurando identificar os temas recorrentes. À medida em que líamos cada narrativa, fomos listando os temas em um quadro. À leitura da narrativa do próximo aluno-professor, aproveitávamos esse quadro, no qual encontrávamos coincidência de temas. Quando surgia um tema novo, inseriámos no quadro relativo à análise individual da narrativa de dado aluno. Certificávamos de que tal novo tema pudesse estar presente também na narrativa de outros alunos. Por fim, justapomos os quadros analíticos individuais, lado ao lado e, onde possível, procedemos à alteração dos temas originalmente encontrados em temas que se aplicassem a todos os alunos. Procedendo dessa forma, pudemos identificar as concepções de leitura e os gêneros textuais mais mencionados nas narrativas e experiências compartilhadas. Por fim, a fim de contextualizar esta pesquisa em um âmbito maior, comparamos os resultados com a pesquisa que problematiza a questão da leitura na formação do indivíduo.

\section{APRESENTAÇÃO DOS RESULTADOS}

\subsection{Relações com a leitura}

Para esta análise, procuramos identificar o que os sujeitos de pesquisa entendem como leitura, a sua função e finalidade. No que diz respeito às relações com a leitura, não foram todos os alunos que demonstraram suas visões explicitamente $(9$, de 16 alunos).

\subsubsection{Leitura como fonte de conhecimento}

Dos nove alunos que expressaram suas concepções de leitura, todos apontaram para a importância dessa habilidade para o desenvolvimento intelectual em diferentes esferas. A seguir, apresentamos alguns excertos das produções dos sujeitos que evidenciam essa visão: 
Reading is the opportunity to learn new information about the world, people, events, places, which enrich our vocabulary. (N1)

Start reading something out of your own interests, you'll see how different types of knowledge will come to you and how you'll acquire new vocabulary. The more you read, the more efficient, smarter you'll become. Start and don't stop reading. $(\mathrm{N} 5)^{5}$

(...) in most professions reading is essential, for the more one reads, the more one learns, and I believe it. (N6)

I think everybody should read a book at least once a month or every two or three months, because when you read, you open your mind, you become more aware of things, you acquire knowledge and you also improve your skills if you read books in another language. (V3) ${ }^{6}$

I believe that reading is a terrific way to improve my language skills and as I want to be a great teacher I must be prepared for different situations I may dump into. (V4) ${ }^{7}$

(...) reading has become a way to understand the world, to survive in class but it hasn't lost its main objective: "To provide knowledge we'll take to the rest of our lives! (V6) ${ }^{8}$

Nos excertos acima, nossa interpretação é de que há relação entre o hábito de leitura e o desenvolvimento da linguagem (N1, N2, V3 e V4). Além disso, os sujeitos também apontam a associação entre este hábito e a vida profissional e/ou acadêmica (N6, V4, V6).

Em N1, interpretamos haver alusão à importância da leitura para o crescimento dos conhecimentos gerais do indivíduo, tendo este aprendizado finalidade de desenvolvimento lexical. O pronome "which" sinaliza a adição de oração na qual N1 expressa um efeito proporcionado pela leitura. Interpretamos que o uso da palavra "opportunity" por N1 indica que isso não depende apenas do indivíduo, mas também de outros fatores externos, que podem facilitar ou dificultar o desenvolvimento do hábito da leitura. N5 também enfatiza o desenvolvimento lexical, apontando também para outros tipos de conhecimento não especificados. Porém, esses dois sujeitos possuem visões diferenciadas no que diz respeito à aquisição do hábito da leitura. N5, diferentemente de N1, aponta para a iniciativa do próprio indivíduo como fator-chave:

\footnotetext{
${ }^{4}$ A leitura é a oportunidade para aprender novas informações sobre o mundo, pessoas, eventos, lugares, que enriquecem nosso vocabulário. (N1)

${ }^{5}$ Comece a ler algo de seus próprios interesses, e você verá como diferentes tipos de conhecimento virão para você e como você irá adquirir novo vocabulário. Quanto mais você lê, mais eficiente e esperto você se tornará. Comece e não pare de ler. (N5)

${ }^{6}$ Eu acho que todo mundo deveria ler um livro pelo menos uma vez por mês ou a cada dois ou três meses, porque quando você lê, você abre a sua mente, você se torna mais consciente das coisas, você adquire conhecimento e você também melhora suas habilidades se você ler livros em outra língua. (V3)

${ }^{7}$ Eu acredito que a leitura é uma maneira incrível de melhorar minhas habilidades linguísticas e como eu quero ser um ótimo professor preciso estar preparado para diferentes situações com as quais posso me deparar. (V4)

${ }^{8}$ (...) a leitura se tornou uma maneira de entender o mundo, de sobreviver em sala de aula mas não perdeu seu principal objetivo: "Fornecer conhecimento que nós levaremos para o resto de nossas vidas!" (V6)
} 
"Start reading something (...)". Rompendo com o gênero narrar, N5 escreve uma frase exortativa, que inicia com o verbo "start", que interpretamos seja seu incentivo (ao leitor) para que a prática de leitura seja iniciada independentemente de fatores externos.

A frequência de leitura é um aspecto enfatizado por N5 e V3. O volume de leitura, para N5, marcado por comparativos, pode levar ao crescimento intelectual (... The more you read, the more efficient, smarter you'll become...). A ideia de volume também interpretamos estar presente na resposta de V3, marcada pela periodicidade e ou frequência do hábito de leitura (everybody should read a book at least once a month or every two or three months). Apesar de ambos apontarem para a leitura como essencial para a aquisição de conhecimento, suas narrativas os diferem no que diz respeito aos tipos de conhecimentos adquiridos. Como já mencionado, N5 aponta para tipos de conhecimento não especificados, enquanto V3 enfatiza os efeitos cognitivos dessa prática (...you open your mind, you become more aware of things ...) e linguísticos estrangeiros (...you also improve your skills if you read books in another language).

Interpretamos haver ideia do desenvolvimento de capacidade de leitura além do texto na narrativa de V6 (... a way to understand the world...), resultado este convergente com a pesquisa de D'Almas (2011). Além disso, V6 aponta para a importância vital da leitura em meio acadêmico (...to survive in class...). O uso da palavra "survive" implica ideia de necessidade da leitura para a progressão dos estudos e, parece-nos, é um indicativo de demandas de aprendizagem em aulas na universidade que podem estar acima da capacidade atual dos alunos. Por outro lado, V4 também relaciona o hábito de leitura ao crescimento acadêmico e profissional (...reading is a terrific way to improve my language skills as I want to be a great teacher ...). Diferentemente de V6, no entanto, V4 avalia leitura acadêmica de maneira positiva, inerente a objetivos pessoais ( ...as I want to be a great teacher I must be prepared for different situations...). N6 relaciona a leitura, assim como V4, ao crescimento profissional, mas de maneira generalizada e impessoal (...in most professions, reading is essential...). Este sujeito não parece avaliar, em seu discurso, este objetivo de leitura como algo positivo ou negativo.

\subsubsection{Leitura como entretenimento}

Interpretamos haver ideia de leitura como entretenimento nas narrativas de três alunos. São eles N7, V6 e V7. 
when I was a child I used to read fairy tales a lot because they were really nice and every child likes them $(\mathrm{N} 7)^{9}$

reading is a way to escape reality and I used to do it. Books carry dreams and many of them use this fact to sell ideas, to sell a kind of life that we wish. $(\mathrm{V} 6)^{10}$

I really like reading what I am interested in, subjects that somehow draw my attention. But being in college, studying to be a better English teacher, is little by little making me like reading theoretical texts as well. (V7) ${ }^{11}$

Podemos perceber, nos excertos de N7 e V6, o uso do passado simples ao se referirem à leitura como entretenimento, ambos utilizando a expressão "used to", indicando que esta visão está relacionada a hábitos de seus passados. No caso de N7, a leitura como entretenimento é exemplificada pelo gênero conto de fadas. V6, por outro lado, não menciona nenhum gênero, mas exalta a capacidade da leitura de estimular o imaginário.

V7, ao contrário de N7 e V6, discorre sobre a leitura como entretenimento no presente. Porém, este aluno indica que a vivência acadêmica modifica suas concepções sobre funções da leitura. O mesmo acontece com N7 e V6:

(...) when I grew up my idea of reading was very different because I had to read some boring books at school (...) (N7) ${ }^{12}$

(...) reading has become a way to understand the world, to survive in class(...) $(\mathrm{V} 6)^{13}$

Interpretamos, também, que estes alunos que possuíam concepção da leitura como entretenimento e tiveram suas visões sobre leitura modificadas, assinalando tais mudanças por atributo (was very different), por compulsoriedade (I had to read), por processos existencial (has become) e mental (to understand the world; ...survive) no mundo material (in class).

\footnotetext{
${ }^{9}$ quando eu era criança eu costumava ler muito contos de fada porque eles eram realmente legais e toda criança gosta deles (N7)

${ }^{10}$ a leitura é uma maneira de escapar da realidade e eu costumava fazer isso. Livros carregam sonhos e muitos deles usam este fato para vender ideias, para vender um tipo de vida que desejamos. (V6)

${ }^{11}$ Eu realmente gosto de ler o que estou interessado, assuntos que de alguma maneira chamam minha atenção. Mas estar na faculdade, estudando para ser um melhor professor de inglês, está pouco a pouco me fazendo ler textos teóricos também. (V7)

${ }^{12}$ (...) quando eu cresci minha ideia sobre a leitura era bem diferente porque eu tive que ler alguns livros chatos na escola (...) (N7)

${ }^{13}$ (...) a leitura se tornou uma maneira de entender o mundo, de sobreviver em sala de aula (...) (V6)
} 


\subsection{Objetos de leitura}

Procuramos identificar, nas narrativas de experiência, os objetos de leitura dos alunos em cada uma de suas fases como leitores, os contextos em que tais leituras foram realizadas e/ou encorajadas, bem como os atores sociais que as incentivaram.

Dividimos as fases como leitor em: infância, adolescência e vida adulta (ou atualidade), de modo que pudéssemos enxergar mais claramente o desenvolvimento dos hábitos de leitura. Esse procedimento nos possibilitou chegar a algumas conclusões sobre as escolhas de leituras dos alunos.

No que diz respeito à infância, interpretamos que os alunos que avaliaram suas experiências como positivas foram influenciados por membros familiares ascendentes ou por profissionais da educação (bibliotecários e professores). Ou seja, o hábito da leitura, se observado em familiares, facilitou o desenvolvimento da leitura da criança no contexto desta pesquisa. Esse resultado particularmente ecoa esforços de pesquisa revisados por Reis (2005).

Entre os gêneros de leitura mencionados por estes alunos, podemos citar histórias em quadrinhos, contos de fadas e literatura infantil em geral, todos em língua materna. Há também a menção de histórias contadas oralmente, bem como transmitidas por meio de CD. Isto indica que os alunos consideram como leitura nos estágios iniciais do aprendizado não apenas a compreensão da palavra escrita, mas também da palavra falada (ex.: histórias infantis).

Esta influência de atores sociais no desenvolvimento da leitura pode ser observada em alguns excertos das narrativas:

\footnotetext{
Luckily, my father sold illustrated books well and drew a lot of my attention. $(\mathrm{N} 6)^{14}$

My mother wanted to put me in the readers' world, because she always told me that a person who reads is the smartest person in the world. (N7) ${ }^{15}$

I remember my mother reading to my sister and me at lunch time, even on school days $(\ldots)(\mathrm{V} 1)^{16}$

(...) I do remember I had those classes at Elementary School, which we used to call "The Tale Time", when the librarian used to take us (I mean, my classmates and me) to the library, have us sit down on the floor, usually there was a beautiful and smooth carpet and I loved to sit on it, and tell us the most amazing stories $(. ..)(\mathrm{V} 7)^{17}$
}

\footnotetext{
${ }^{14}$ Por sorte, meu pai vendia livros ilustrados bem e chamava muito a minha atenção. (N6)

${ }^{15}$ Minha mãe queria me colocar no mundo dos leitores, porque ela sempre me disse que a pessoa que lê é a pessoa mais esperta do mundo. (N7)

${ }^{16}$ Eu lembro da minha mãe lendo para a minha irmã e eu na hora do almoço, mesmo nos dias de aula (...) (V1)

17 (...) Eu lembro que tinha aquelas aulas no ensino fundamental, as quais costumávamos chamar de "A Hora do Conto", quando o bibliotecário costumava nos levar (quero dizer, meus colegas e eu) para a
} 
Nos três primeiros excertos apresentados acima, identificamos a influência familiar de diferentes maneiras: N6 parece ter se desenvolvido em um meio onde os livros o cercavam e isto exerceu influência no que diz respeito à aquisição do hábito da leitura; N7, influenciado pela mãe, iniciou sua trajetória de leitura, pois tinha ciência da importância cultural desse ato; já V1, também influenciado pela mãe, provavelmente desenvolveu o hábito de ler após ter contato com as histórias contadas oralmente. V7, diferentemente dos três outros sujeitos, iniciou sua trajetória de leitura na escola, em um ambiente onde a leitura parecia não estar relacionada a disciplinas regulares, portanto em um contexto que provavelmente valorizava as histórias como entretenimento e incentivo ao hábito da leitura.

Por outro lado, os indivíduos que relataram não terem tido nenhuma espécie de incentivo à leitura na infância retratam suas experiências como negativas. Podemos exemplificar com dois excertos:

In my childhood my parents didn't encourage me to read, I think they had an idea that if I was capable to read and that learning from my school textbooks was enough for my age. (V8) ${ }^{18}$

The experiences I can recall as a reader started at school. When I was asked to do some assignments, I always had difficulty in summarizing the main ideas as I thought all information on the text was important. Then I used to copy everything from it. Moreover, until the $8^{\text {th }}$ grade, I only read literature books in order to do school assignments. (N3) ${ }^{19}$

Nesses excertos extraídos das narrativas de V8 e N3, assinalamos a ausência de incentivo familiar enfatizada no primeiro, enquanto no segundo tal incentivo não é sequer mencionado. V8 parece considerar o tratamento que seus ascendentes deram à leitura em sua educação como errônea, permitindo-nos inferir que V8 não compartilha dessa visão. N3 relata dificuldades na compreensão textual e relaciona sua prática de

biblioteca, nos sentar no chão, normalmente havia um tapete lindo e macio e eu amava sentar nele, e nos contar as histórias mais incríveis (...) (V7)

${ }^{18} \mathrm{Na}$ minha infância meus pais não me encorajaram a ler, eu acho que eles tinham a ideia de que se eu era capaz de ler e que aprender de livros didáticos era o suficiente para a minha idade. (V8)

19 As experiências que consigo lembrar como leitor começaram na escola. Quando era pedido que eu fizesse tarefas, eu sempre tive dificuldade em sumarizar as principais ideias já que eu pensava que toda as informações do texto eram importantes. Então eu costumava copiar tudo destes textos. Além disso, até a oitava série, eu só li livros de literatura para realizar tarefas escolares. (N3) 
leitura na infância apenas com o objetivo de realizar tarefas escolares, uma finalidade prática e não recreativa.

No período da adolescência, podemos identificar um papel negativo da instituição formativa no desenvolvimento dos sujeitos da pesquisa. O efeito negativo na formação de leitores foi apontado por Reis (2005) em sua revisão da literatura sobre a pesquisa no campo da mudança educacional. No geral, os alunos V5, V9 e N7 indicam a leitura na escola como obrigação, e exemplificam isso, citando cânones da literatura em língua materna. Alguns excertos ilustram esta interpretação:

I really had to read many books, even if I didn't like it. (V5) 20

(...) I started the school life, it could be a great opportunity to enjoy learning to read but as most of the public school students I didn't enjoy it. (V9) ${ }^{21}$

When I was a teenager I hated reading, because I had to read some Brazilian literature books in the elementary school (...) (N7) ${ }^{22}$

Os trechos acima enfatizam o aspecto de obrigação da leitura na escola e o relacionam a algo negativo. V5 menciona a quantidade de leitura exigida (uso de modal deôntico had to) e dá a entender que o tipo de leitura na escola incluia opções que não foram de seu agrado (uso do advérbio even if); V9 demonstra opinião de que sua experiência negativa é compartilhada por seus pares no contexto público de ensino (uso da oração comparativa as most of the public school students... ). O aluno N7, por fim, relaciona a sua pouca afinidade (uso de processo mental I hated reading; uso do modal deôntico had to) com a leitura na escola aos gêneros requeridos em tal contexto, livros de literatura vernácula.

Foram mencionados, também, gêneros como literatura juvenil de autoria estrangeira, literatura juvenil em língua materna e publicações para jovens. Estes gêneros aparecem geralmente vinculados a preferências pessoais dos alunos, que, portanto, avaliam positivamente suas experiências com tais gêneros de leitura.

(...) making my reading choices myself, I enjoyed reading books for teenagers, such as "The Princess Diary", and all books by the same author. (N2) 23

I used to buy foreign music magazines (...) to read features about my favorite bands. $(\mathrm{V} 1)^{24}$

\footnotetext{
${ }^{20}$ Eu realmente tinha que ler vários livros, mesmo que não gostasse disso. (V5)

21 (...) Eu comecei a vida escolar, poderia ser uma ótima oportunidade para aprender a ler mas como a maioria dos alunos de escolas públicas eu não gostava disso. (V9)

${ }^{22}$ Quando eu era adolescente eu odiava ler, porque eu tinha que ler alguns livros de literatura brasileira no ensino fundamental (...) (N7)

${ }^{23}$ (...) fazendo minhas próprias escolhas de leitura, eu gostava ler livros para adolescentes, como "O Diário da Princesa", e todos os livros do mesmo autor. (N2)

${ }^{24} \mathrm{Eu}$ costumava comprar revistas estrangeiras de música (...) para ler artigos sobre minhas bandas favoritas. (V1)
} 
When I grew older, my interest on books, mainly romance and sci-fi grew too. I always read romance books from Brazilian and American authors, but the stories were always written in Portuguese. (V3) ${ }^{25}$

Pelos excertos acima, interpretamos agência dos alunos, enquanto leitores, em relação ao hábito de leitura, pois suas narrativas trazem excertos que os mostram se movendo voluntariamente a gêneros resultantes de suas próprias escolhas, sendo estas motivadas por seus interesses e gostos particulares e não necessariamente vinculadas a instituições educacionais formais ou à influência de ascendentes familares na fase da adolescência. Daí interpretarmos que a leitura, para N2, V1 e V3, visa ao entretenimento. N2 discorre sobre suas "escolhas de leitura" (reading choices), V1 relaciona a leitura de revistas estrangeiras sobre música às suas bandas musicais favoritas, e V3 especifica os gêneros que lhe interessavam sem, entretanto, mencionar o que o/a levou a esta predileção

Por fim, em se tratando da vida adulta, os alunos narram suas experiências de leitura no ensino superior. Entre os gêneros frequentemente citados estão publicações especializadas (ex.: periódicos e artigos científicos) tanto em língua materna quanto em língua estrangeira. Alguns alunos veem esta leitura acadêmica como algo positivo; outros, como negativo.

No aspecto de avaliação, interpretamos não haver uma opinião predominante. É importante mencionar que, apesar de alguns alunos avaliarem estas experiências como positivas, associamos estas leituras à finalidade prática. $\mathrm{Na}$ vida adulta desses alunos adultos, a presença da leitura para entretenimento é pouco mencionada. Ilustramos com os excertos abaixo a finalidade prática da leitura para os alunos na fase adulta:

\begin{abstract}
As an adult, I could be more involved in reading than before, I mean, reading academic papers for discussion, reflection, and improvement of my language skills. $(\mathrm{N} 1)^{26}$

Now I read books in English, not just because I need to read but I really like, I think it's very important and helpful. (V2) ${ }^{27}$

(...) at the University we have to read so many articles and think about them. It is a different phase, the habit of reading follows our objectives and reading has become a way to understand the world, to survive in class (...) (V6) ${ }^{28}$
\end{abstract}

\footnotetext{
${ }^{25}$ Quando eu cresci, meu interesse em livros, principalmente romance e ficção científica também cresceu. Eu sempre li livros de romance de autores brasileiros e americanos, mas as histórias eram sempre escritas em português. (V3)

${ }^{26}$ Como adulto, eu pude me envolver mais com a leitura do que antes, quero dizer, ler artigos acadêmicos para discussão, reflexão e melhora das minhas habilidades linguísticas. (N1)

${ }^{27}$ Agora leio livros em inglês, não só porque eu preciso ler mas eu gosto bastante, eu acho que isso é muito importante e útil. (V2)

${ }^{28}$ (...) na Universidade temos que ler tantos artigos e pensar sobre eles. É uma fase diferente, o hábito da leitura segue nossos objetivoss e a leitura se tornou uma maneira de entender o mundo, de sobreviver em sala de aula (...) (V6)
} 
No relato de N1, vinculamos as finalidades da leitura acadêmica à negociação, interação oral (discussion), a processos e alcances cognitivos e linguísticos (reflection; improvement of my language skills). $\mathrm{O}$ aluno $\mathrm{V} 2$ atenta destaca a importância desse tipo de leitura (uso de intensificador de atributos em very important and helpful). Já V6 atenta para uma mudança paradigmática, mencionando a necessidade de reflexão em meio acadêmico (uso de atributo em different phase) e o imperativo da habilidade leitora para acompanhar demandas da universidade (survive in class).

No quadro a seguir, expomos a síntese de nossas interpretações:

Quadro 1: Fases de formação de leitores: atores e instituições, objetos, gêneros e finalidades da leitura.

\begin{tabular}{|c|c|c|c|c|}
\hline Fase & $\begin{array}{c}\text { Atores/ } \\
\text { Instituições }\end{array}$ & Objetos & Gêneros & Finalidades \\
\hline Infância & $\begin{array}{l}\text { Pais, professores } \\
\text { e bibliotecários }\end{array}$ & $\begin{array}{c}\text { Livros e } \\
\text { ascendentes } \\
\text { (familiares e } \\
\text { escolares) }\end{array}$ & Literários & $\begin{array}{c}\text { Entretenimento e } \\
\text { incentivo à formação } \\
\text { de hábito }\end{array}$ \\
\hline \multirow[t]{2}{*}{ Adolescência } & Escola & Livros & Literários & $\begin{array}{c}\text { Conhecimento } \\
\text { cultural }\end{array}$ \\
\hline & $\begin{array}{l}\text { Os próprios } \\
\text { leitores }\end{array}$ & Livros e CDs & $\begin{array}{l}\text { Literários e } \\
\text { musicais }\end{array}$ & Entretenimento \\
\hline \multirow[t]{2}{*}{ Vida Adulta } & $\begin{array}{l}\text { Instituição de } \\
\text { ensino superior }\end{array}$ & \multirow[t]{2}{*}{$\begin{array}{c}\text { Artigos } \\
\text { científicos }\end{array}$} & \multirow[t]{2}{*}{ Científicos } & $\begin{array}{l}\text { Conhecimento } \\
\text { profissional } \\
\text { Prática }\end{array}$ \\
\hline & $\begin{array}{l}\text { Os próprios } \\
\text { leitores }\end{array}$ & & & Pessoal \\
\hline
\end{tabular}

\section{DISCUSSÃO FINAL}

Neste estudo, procuramos interpretar o desenvolvimento de alunos do segundo ano do curso de Letras - Inglês e Respectivas Literaturas da UEL, enquanto leitores em diferentes fases - da infância à vida adulta. Tendo interpretado dados foram produzidos por meio de narrativas escritas de experiência desses alunos, focalizamos atores e/ou instituições fomentadoras da leitura, objetos de leitura, gêneros lidos e finalidades da leitura em cada fase.

Nossas interpretações sublinham a relevância de atores sociais ascendentes, tais como membros familiares e profissionais da educação para aquisição do hábito da leitura na infância. Os leitores que relataram encorajamento à leitura na infância 
apresentaram visão positiva em relação ao hábito, enquanto os que não relatam tal incentivo tendem a apresentar ausência de leituras de entretenimento nos períodos subsequentes - na adolescência e vida adulta.

Os alunos que relataram terem cultivado o hábito da leitura na infância apresentaram mais variados gêneros lidos na adolescência, enquanto os não incentivados a ler na infância continuaram com visão negativa na adolescência, aparentemente tendo tido experiências de leitura relacionadas apenas à literatura funcional, com finalidade de aquisição de conhecimento cultural e não à literatura recreativa (de entretenimento). O construcionisma social Triplett (2004) considera que o desenvolvimento do hábito de leitura se dá nos diferentes ambientes pelos quais o indivíduo circula. Howard (2010) menciona estudos anteriores que apontam que, se a criança estiver inserida em um ambiente de não leitores, terá mais tendência a ser um não-leitor, apresentando semelhança aos nossos resultados. Do mesmo modo, crianças com pais leitores terão mais possibilidades de serem leitores. Estas pesquisas, portanto, apontam a importância do incentivo à leitura desde os anos iniciais de vida, o que é também verificado em nosso estudo.

Já na adolescência, os sujeitos que apresentaram visão positiva da leitura na infância seguiram com este hábito, porém, com gêneros diferentes. De acordo com Hopper (2005), é comum adolescentes escolherem materiais de leitura com os quais possuem algum nível de identificação pessoal. Desse modo, justifica-se a predominância, nos resultados desta pesquisa, de menções a livros de literatura estrangeira direcionada a jovens. Pode-se explicar também a diferença entre os livros relatados como sendo de leitura de recreação e as leituras escolares, pois as escolhas de professores geralmente estão distantes dos interesses do adolescente (THOMSON, 1987 apud HOPPER, 2005).

Destacamos que é na adolescência que os alunos narraram exercer ações que interpretamos ser agência enquanto leitores. Eles tomaram iniciativa e fizeram escolhas em relação à leitura, ao que liam. Essa agência está presente particularmente em narrativas de alunos em cuja biografia estiveram presentes ascendentes que lhes incentivaram a leitura e ambientes cercados de fontes de leitura.

$\mathrm{Na}$ vida adulta, as narrativas relataram foco na leitura acadêmica. Interpretamos a leitura nesta fase como processo voltado à aquisição de conhecimento profissional. As narrativas dos alunos não apenas mostram que percebem a mudança de gêneros de leitura, que passam a ser de textos científicos, voltados à sua preparação e embasamento 
profissional, mas também deixam ou ausentes menções de apreciação a esses tipos de gêneros de leitura ou revelam que a leitura é ponto de apoio em sua sobrevivência na sala de aula do curso de graduação. Registramos, também, narrativas de alunos que valorizam esses gêneros de leitura na fase de vida adulta e talvez seja a tarefa solicitada de escrever narrativa intitulada "O leitor que me tornei" instrumento catalisador de reflexão e de autodescoberta com respeito a suas identidades de leitores e futuros professores.

Destacamos que é tanto na adolescência quanto na vida adulta que as narrativas dos leitores marcam o aspecto compulsório de gêneros de leitura distantes de seu gosto pessoal. A revisão da literatura feita pela pesquisa doutoral de Reis (2005) registra que a escola exerce papel negativo no desenvolvimento de leitores e do gosto pelo leitura.

Sabemos que, uma vez que professores que não possuem uma relação afetiva com a leitura, dificilmente influenciarão seus alunos na aquisição deste hábito (BARROS; GOMES, 2008). Ademais, conforme nossa análise, profissionais da educação têm papel relevante no processo no desenvolvimento do gosto pela leitura como recreação por parte dos alunos. No que tange a educação de professores para ensino de leitura, a literatura profissional informa que educadores que não vivenciaram as visões de leitura que pretendem ensinar a seus alunos, não conseguem ensiná-las, pois não possui o conhecimento experiencial necessário para realizar tal tarefa.

Neste trabalho, restringimos nossa análise sobre as narrativas escritas pelos alunos. Razões sociais e/ou demográficas para oferecermos explicações aos resultados de nossas interpretações fogem ao nosso propósito. Para oferecer esse tipo de explicação, são necessários estudos especialmente desenhados para esse fim.

A pesquisa de D’Almas revela que o dialogismo entre educadora de professores e alunos do curso de Letras, em contexto de preparação para ensino de leitura, a partir de sua consciência crítica da linguagem, é apontado como importante fator no desenvolvimento da capacidade crítica de alunos enquanto leitores e futuros professores.

Como pesquisadores construcionistas sociais, dirigimos a contribuição deste estudo à comunidade de educadores de professores e professores em fase de educação inicial e continuada. Além disso, oferecemos como sugestões de pesquisas futuras estes opostos binários extraídos de nossas interpretações feitas no presente estudo: presença $\mathrm{x}$ ausência; incentivo x obrigação; liberdade x compulsoriedade; proximidade x distância, que podem ser explorados em pesquisas futuras. 
Em conclusão a este estudo, lançamos questões a serem pensadas nos cursos de educação de professores em seus diversos níveis de preparação: que liberdade em relação à leitura têm os leitores com quem interajo? Leituras de caráter compulsório visando à formação profissional têm contribuído para fortalecer ou para enfraquecer o desejo de ler? É o gênero de leitura, o texto escolhido ou a interação em sala de aula, mediada pelas visões de leitura de cada um, que fortalece ou enfraquece o desenvolvimento de leitores independentes e críticos?

\section{REFERÊNCIAS}

BAKHTIN, M. Estética da Criação verbal. São Paulo: Martins Fontes, 1992.

BARROS, T. N.; GOMES, E. O perfil dos professores leitores nas séries iniciais e a prática de leitura em sala de aula. $C E F A C$, São Paulo, v.10, n.3, 332-342, jul-set, 2008.

BENJAMIN, W. O Narrador. Considerações sobre a Obra de Nikolai Leskov. In Obras Escolhidas I. Magia e Técnica, Arte e Política. São Paulo: Brasiliense, 1996.

BRONCKART, J. Atividade de linguagem, textos e discursos : por um interacionismo sociodiscursivo. $1^{a}$ ed. Trad. Anna Rachel Machado. São Paulo: Educ, 1999.

D'ALMAS, J. Leitura Crítica: um estudo da aprendizagem de alunos

de inglês. 2011. 152f. Dissertação (Mestrado em Estudos da Linguagem) Universidade Estadual de Londrina, Londrina.

HALLING, S.; LAWRENCE, C. Homogenizing the world, negating embodied experience. Journal of Theoretical and Philosophical Psychology, vol. 19(1), 1999, p. 78-89.

HOPPER, R. What are teenagers reading? Adolescent fiction reading habits and reading choices. Literacy, 2005, p. 113-120.

HOWARD, V. Peer Influences on Young Teen Readers. Young Adult Library Services, 2010, p. 34-41.

FAIRCLOUGH, N. Language and Power. London: Longman, 1989.

FAIRCLOUGH, N. Discourse and Social Change. Cambridge: Polity Press, 1992.

FOWLER, R. On critical linguistics. In CALDAS-COULTHARD, C. R., COULTHARD, M. (Eds.).Texts and practices: Readings in critical discourse analysis. London: Routledge, 1996.

LABOV, W. Some Further Steps in Narrative Analysis. Disponível em: < http://www.ling.upenn.edu/ wlabov/sfs.html>. Acesso em: 5 ago. 2013.

MARCUSCHI, L. A. Gêneros textuais: definição e funcionalidade. In: DIONÍSIO, A. et al. Gêneros textuais e ensino. Rio de Janeiro: Lucerna, 2002.

NATHANSON, S. et al. The Reading Habits and Literacy Attitudes of Inservice and Prospective Teachers: Results of a Questionnaire Survey. Journal of Teacher Education, v. 59, 2008, p. 313-321.

OZYLDIRIM, I. Narrative analysis: An analysis of oral and written strategies in personal experience narratives. Journal of Pragmatics, vol. 41, 2009, p. 1209-1222. 
REIS, S. 2005. Learning to teach reading in English as a foreign language : an interpretive study of student teachers' cognitions and actions. 285f. Tese (Doutorado) - Radboud University Nijmegen, Holanda.

SCHWANDT, T. Três posturas epistemológicas para a investigação qualitativa: interpretativismo, hermenêutica e construcionismo social, in DENZIN, N. K. , LINCOLN, Y. S. e colaboradores. O planejamento da pesquisa qualitativa: teorias $e$ abordagens, Porto Alegre: Bookman e Artmed, 2006.

TRIPPLET, C. F. Looking for a struggle: Exploring the emotions of a middle school reader. International Reading Association, 2004, p. 214-222.

VAN DIJK, T. Critical Discourse Analysis. Disponível em: < www.discourses.org/OldArticles/Critical\%20discourse\%20analysis.pdf >. Acesso em: 5 ago. 2013.

WALLACE, C. Critical literacy awareness in the EFL classroom. In FAIRCLOUGH, N. (Ed.), Critical language awareness. Harlow: Longman, 1992. 